\title{
Feasibility and reliability of an automated controller of inspired oxygen concentration during mechanical ventilation
}

\author{
Kaouther Saihi ${ }^{1,2}$, Jean-Christophe M Richard ${ }^{1}$, Xavier Gonin ${ }^{1}$, Thomas Krüger ${ }^{2}$, Michel Dojat ${ }^{3}$ and Laurent Brochard ${ }^{1,4^{*}}$
}

\begin{abstract}
Introduction: Hypoxemia and high fractions of inspired oxygen $\left(\mathrm{FiO}_{2}\right)$ are concerns in critically ill patients. An automated $\mathrm{FiO}_{2}$ controller based on continuous oxygen saturation $\left(\mathrm{SpO}_{2}\right)$ measurement was tested. Two different $\mathrm{SpO}_{2}-\mathrm{FiO}_{2}$ feedback open loops, designed to react differently based on the level of hypoxemia, were compared. The results of the $\mathrm{FiO}_{2}$ controller were also compared with a historical control group.

Methods: The system measures $\mathrm{SpO}_{2}$, compares with a target range (92\% to 96\%), and proposes in real time $\mathrm{FiO}_{2}$ settings to maintain $\mathrm{SpO}_{2}$ within target. In 20 patients under mechanical ventilation, two different $\mathrm{FiO}_{2}-\mathrm{SpO}_{2}$ open loops were applied by a dedicated research nurse during 3 hours, each in random order. The times spent in and outside the target $\mathrm{SpO}_{2}$ values were measured. The results of the automatic controller were then compared with a retrospective control group of $30 \mathrm{ICU}$ patients. $\mathrm{SpO}_{2}-\mathrm{FiO}_{2}$ values of the control group were collected over three different periods of 6 hours.

Results: Time in the target range was higher than 95\% with the controller. When the 20 patients were separated according to the median $\mathrm{PaO}_{2} / \mathrm{FiO}_{2}$ (160(133-176) mm Hg versus 239(201-285)), the loop with the highest slope was slightly better $(P=0.047)$ for the more-hypoxemic patients. Hyperoxemia and hypoxemia durations were significantly shorter with the controller compared with usual care: $\mathrm{SpO}_{2}$ target range was reached $90 \%$ versus $24 \%$, 27\% and 32\% $(P<.001)$ with the controller, compared with three historical control-group periods.
\end{abstract}

Conclusion: A specific $\mathrm{FiO}_{2}$ controller is able to maintain $\mathrm{SpO}_{2}$ reliably within a predefined target range. Two different feedback loops can be used, depending on the initial $\mathrm{PaO}_{2} / \mathrm{FiO}_{2}$; with both, the automatic controller showed excellent performance when compared with usual care.

\section{Introduction}

Oxygen is essential for life. As has any drug, it has consequences in case of under- and overdosing. In adult intensive care patients, hypoxemia is a primary preoccupation for all clinicians. The consequences of hyperoxemia are more often neglected because they have been poorly explored. Several clinical observations have suggested that liberal administration of oxygen can be toxic [1-3]. Hyperoxia induces the constitution of free oxygen radicals that may cause endothelial cell injury and increases the

\footnotetext{
* Correspondence: Brochardl@smh.ca

'Intensive Care Unit, Department of Anesthesiology, Pharmacology and Intensive Care, Geneva University Hospital, Geneva, Switzerland

${ }^{4}$ Critical Care Department, St Michael's Hospital, Toronto; InterDepartmental Division of Critical care Medicine University of Toronto, Toronto, Canada Full list of author information is available at the end of the article
}

presence of inflammatory cells [4]. It can lead to absorption atelectasis in lung regions with low ventilation-to-perfusion ratios [5]. In adult intensive care patients, it has been shown that exposure to hyperoxemia may be harmful in specific populations. In post-cardiac arrest patients, arterial hyperoxemia was independently associated with in-hospital mortality, to an extent comparable to hypoxemia [6]. In nonventilated severe COPD patients with exacerbation, high $\mathrm{FiO}_{2}$ can be responsible for hypercapnia but also increased mortality [7]. In patients with severe traumatic brain injury, hyperoxemia is associated with increased mortality and worse outcomes [8].

Based on these concerns and the possibility that optimizing oxygenation targets may improve patients' outcome, systems for automatic adjustment of $\mathrm{FiO}_{2}$ based on $\mathrm{SpO}_{2}$ measurement might be of great value to optimize care.

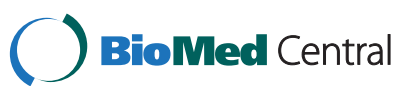


With the use of pulse oximetry and computer technology, several attempts have been made to automate the adjustment of $\mathrm{FiO}_{2}$, especially in neonatology, because of the frequent and unpredictable change of oxygenation and risks of hyperoxemia in premature babies [9-12]. In adults, preliminary attempts at closed-loop control of oxygenation were developed and used in military trauma patients, as well as for titrating the $\mathrm{FiO}_{2}$ for COPD patients requiring long-term oxygen therapy [13-15]. These systems proved a reduction in oxygen use without inducing hypoxemia compared with conventional adjustments. Recently, an automated oxygen-flow titration was tested on healthy subjects during induced hypoxemia and showed a significant reduction of hypoxemia and hyperoxemia compared with classic constant-flow oxygen administration [16]. Last, a recent mode of ventilation allows full control of both pressure-targeted breaths and the level of $\mathrm{FiO}_{2}$ in a closed-loop manner. Two recent clinical studies showed the feasibility of this technique $[17,18]$.

To overcome the challenges of continuously maintaining an adequate oxygenation in adult ICU patients, we developed an automated oxygen-controller prototype that aims to maintain the measured $\mathrm{SpO}_{2}$ in a predefined target range [92\% to 96\%]. For this system, we defined two different $\mathrm{FiO}_{2}-\mathrm{SpO}_{2}$ feedback profiles with the hypothesis that the more-severely hypoxemic patients, because of intrapulmonary shunt, are less sensitive to $\mathrm{FiO}_{2}$ changes and need larger changes in $\mathrm{FiO}_{2}$ than do less-hypoxemic patients. The first aim of the current study was to test and compare these two different $\mathrm{SpO}_{2}-\mathrm{FiO}_{2}$ profiles in patients with different degrees of hypoxemia to maintain $\mathrm{SpO}_{2}$ in the predefined target range [92\% to 96\%]. To evaluate the clinical impact of the system, we also compared the results obtained with these two profiles of the $\mathrm{FiO}_{2}$ controller with usual care based on a comparable historical control group.

\section{Materials and methods Study design and patients}

The study was conducted in the medical-surgical ICU of Geneva University Hospital. The first part of the study was a prospective trial performed in 20 ICU patients, and the second part included a retrospective analysis of consecutive admitted patients between September and October 2011 in the same ICU. The two parts of the study were accepted by the Ethics Committee of the hospital [The Ethic Committee and Research on Human Beings (CEREH), research project number 12089(NAC12040)].

For the first part, signed informed consents were obtained from the patient when possible or from the family, and from the attending physician. For both parts, inclusion criteria were similar and mechanically ventilated patients for more than 48 hours after ICU admission older than 18 years old. Patients with severe acidosis $(\mathrm{pH} \leq 7.20)$, hemodynamic instability, serum lactate $>3 \mathrm{mmol} / \mathrm{L}$, or need for norepinephrine infusion $\geq 0.5 \mu \mathrm{g} / \mathrm{kg} / \mathrm{min}$, pregnant, or with intracranial hypertension were not included. Concerning the second part, $\mathrm{SpO}_{2}$ had to be recorded continuously to ensure the selection of the patient for the control group.

\section{The automated $\mathrm{FiO}_{2}$ controller}

The $\mathrm{FIO}_{2}$-controller prototype tested in the present study included software implemented in a medical PC connected via RS-232 serial links to a ventilator (Evita XL; Dräger Medical, Lübeck, Germany) and to a pulse oximeter (Radical 7; Masimo Corp, Irvine, CA, USA) set at an averaging interval of 2 seconds. A probe was placed on the finger of the patient while we used an ear probe in case of poor perfusion, as indicated by the perfusion index of the Masimo. The perfusion index (PI) which is the ratio of the pulsatile blood flow to the nonpulsatile or static blood in peripheral tissue, was calculated continuously by the Masimo. A threshold of low signal and unreliable measurement was defined as signal index quality (SIQ) $<0.30$, where the latter represents Masimo's quality indicator in case of extremely low perfusion and motion conditions [19]. When SIQ was $<0.30$, the $\mathrm{FiO}_{2}$ controller kept the last $\mathrm{FiO}_{2}$ before this low SIQ value.

The serial link connected to the pulse oximeter allowed a continuous recording of $\mathrm{SpO}_{2}$ values, as well as heart rate, perfusion index, $\mathrm{SIQ}$, and $\mathrm{SpO}_{2}$ alarms every second. With the same frequency, $\mathrm{FiO}_{2}$ values measured on the inspiratory nozzle and set on the ventilator were acquired from the ventilator. The proposed $\mathrm{FiO}_{2}$ adjustments were indicated by an acoustic signal and displayed on the screen of the medical PC every 30 seconds. The purpose of the present study was to test the reliability of the system working in an open loop. To achieve this goal, a fully dedicated ICU research nurse executed the adjustments on the ventilator. He could deviate from any proposal if it was considered to be unsafe, according to his clinical judgment.

The target for the controller is the midpoint between the high (96\%) and low (92\%) $\mathrm{SpO}_{2}$ targets (that is, 94\%). The automatic $\mathrm{FiO}_{2}$ controller compares the measured $\mathrm{SpO}_{2}$ with the target $94 \%$ and calculates the difference to control the delivered $\mathrm{FiO}_{2}$ set to the patient.

The delivered $\mathrm{FiO}_{2}$ depends on the selected version of the algorithm. These latter are two tables that define for each $\mathrm{SpO}_{2}$ deviations $\left(\Delta \mathrm{SpO}_{2}\right)$ an $\mathrm{FiO}_{2}$ step change (either increase or decrease) to be applied to the current $\mathrm{FiO}_{2}$. These two different tables define the two slopes of $\mathrm{SpO}_{2}-\mathrm{FiO}_{2}$ tested in this study. The difference is based on the fact that we hypothesized that, for severely hypoxemic patients, a larger change or step in $\mathrm{FiO}_{2}$ is required than for less-hypoxemic patients because intrapulmonary shunt makes those patients less "sensitive" to $\mathrm{FiO}_{2}$ changes. 
After changing $\mathrm{FiO}_{2}$, a predefined time of 30 seconds has to expire before changing $\mathrm{FiO}_{2}$ is allowed. To react immediately in case of a severe hypoxemic event, the controller applies $100 \%$ of $\mathrm{FiO}_{2}$ when $\mathrm{SpO}_{2}<85 \%$. This reaction is the same in the two versions of the algorithm.

For avoiding instabilities (that is, oscillations, overshoots), the reaction of the $\mathrm{FiO}_{2}$ controller is dampened based on physiological and technical delays. Because of this dampening of the controller, early adjustments every 30 seconds were possible. The controller is based on a conventional Proportional-Integral-Derivative (PID) control using both the $\mathrm{SpO}_{2}-\mathrm{FiO}_{2}$ slopes and $\Delta \mathrm{FiO}_{2}$ step changes, based on an estimated effective $\mathrm{FiO}_{2}$.

\section{Study protocol}

The study was composed of two parts: a prospective trial and a retrospective analysis.

\section{First part, prospective trial}

The first part of the study consisted of a prospective crossover trial that aimed to compare the usefulness of two feedback open-loop profiles for the $\mathrm{FiO}_{2}$ controller. The trial corresponded to two 3-hour periods applied in randomized order, with $\mathrm{FiO}_{2}$ adjusted according to each profile by a research nurse. As the main difference between the two profiles is the $\mathrm{SpO}_{2} / \mathrm{FiO}_{2}$ slope, we tested the clinical difference of using these two different slopes. During all study periods, the $\mathrm{SpO}_{2}$ target range was $92 \%$ to $96 \%$. This range was consistent with previous clinical publications on automatic $\mathrm{FiO}_{2}$ controllers $[13,14,16,20]$. It was considered a reasonable compromise that combines safety (limiting risk of hypoxemia) and efficacy to limit $\mathrm{FiO}_{2}$ in comparison to usual care, and which was also used in the control ICU. This was important for the comparison between the two groups in the study (study group and historical control group). A research nurse was fully dedicated for the $\mathrm{FiO}_{2}$ adjustments and remained at the bedside during each trial. Meanwhile, patients continued to receive usual care and ventilator parameters such as positive end-expiratory pressure (PEEP), were kept constant unless the clinician asked for changes. In two patients, a change of PEEP was required.

All patients were ventilated with the same ventilator (Evita XL) and were randomly allocated to an order for the two profiles by opening a sealed envelope. During the recordings, endotracheal suctioning could be needed. Before any suctioning, $\mathrm{FiO}_{2}$ was increased to $100 \%$. This was obtained automatically in the first five patients (preoxygenation procedure function of the ventilator). However, this approach was not consistently used by the nurses because it was not a systematic standard approach for all patients. Therefore, we decided to recommend doing it manually in the 15 other patients, with $\mathrm{FiO}_{2}$ subsequently decreased by following the
$\mathrm{FiO}_{2}$ controller suggestions. These episodes produced major changes in $\mathrm{FiO}_{2}$ and $\mathrm{SpO}_{2}$ (especially in the high range) over a short period, introducing noise in the signal and reducing the sensitivity of the comparison. We decided against keeping it in the comparison because we were expecting only small changes between the two profiles. We therefore removed for the comparison of the two profiles a period of 15 minutes for each episode of suctioning (it usually took between 5 and 10 minutes to come back to the preceding level) corresponding to the preoxygenation and suctioning maneuvers.

For each patient, we selected the blood gases and ventilation parameters measured at baseline (in the morning). The 20 patients were separated into two groups of 10 according to the median $\mathrm{PaO}_{2} / \mathrm{FiO}_{2}$ ratio: a moderately hypoxemic group with $\mathrm{PF}>188 \mathrm{~mm} \mathrm{Hg}$ and a severely hypoxemic group with $\mathrm{PF} \leq 188 \mathrm{~mm} \mathrm{Hg}$.

\section{Second part}

The second part of the study consisted of a retrospective data collection of an historical group composed of 30 patients admitted in the ICU before the start of the clinical protocol and ventilated at least 48 hours. The nurse:patient ratio during this period was 1:1 or 1:2, depending on the severity of the patient's condition. Concerning $\mathrm{FiO}_{2}$ adjustments in the ICU, no explicit limitations were placed on the usual care, except a prescribed low $\mathrm{SpO}_{2}$ threshold for all patients. Thus, $\mathrm{FiO}_{2}$ settings in the historical control group were dependent on the physician or nurse in charge and could be reduced to $21 \%$ if necessary. Data were collected from a patient data-management system (Centricity Critical Care Clinisoft GE Healthcare) over three different periods of 6 hours (at admission, after 24 hours, at day 7). In this group, $\mathrm{SpO}_{2}$ values were recorded every 1 to 2 minutes. We were especially interested to the data obtained after 24 hours and at day 7 , because our patients in the first part were studied after several days of mechanical ventilation. Patients' identifying information was removed to keep them completely anonymous. In this control group, a subgroup of 17 patients had a minimal clinical threshold of $\mathrm{SpO}_{2} \geq 92 \%$ specifically ordered by the clinician until the day 7 after admission; this subgroup was also compared with the $\mathrm{FiO}_{2}$ controller because the latter has the same low threshold for $\mathrm{SpO}_{2}$.

We could not precisely identify the suctioning periods in the control group, and therefore, for this analysis, suctioning maneuvers, and preoxygenation periods were kept in both groups (study group and the historical control group) for the analysis. For the control group, $\mathrm{SpO}_{2}$ was measured with a pulse-oximetry system (Intellivue MP70 monitor; Philips Medical Systems, Amsterdam, The Netherlands). $\mathrm{SpO}_{2}$ data recorded from the system contained very low values, which carried a high probability of not being real. 
This hypothesis was confirmed when compared with Masimo's recordings, in which $\mathrm{SpO}_{2}$ values were almost always $\geq 80 \%$. We therefore defined aberrant values as $\mathrm{SpO}_{2}<80 \%$ as corresponding to erroneous measurements or artifacts, and we removed them from all the recordings of this group.

\section{Patient data and analysis}

For both groups, we collected the same baseline characteristics including the Acute Physiology and Chronic Health Evaluation (APACHE) II and the Simplified Acute Physiology Score (SAPS) II at the day of admission. Blood gases and care procedures were documented from nursing and medical records. The first arterial blood gases at the day of admission for the historical group and in the morning for the study group were selected to define the baseline values of $\mathrm{pH}, \mathrm{PaO}_{2}, \mathrm{PaCO}_{2}, \mathrm{SaO}_{2}$, and to calculate the $\mathrm{PaO}_{2} /$ $\mathrm{FiO}_{2}$ ratio. Ventilator settings and modes in addition to monitored measurements, including $\mathrm{SpO}_{2}$ and $\mathrm{FiO}_{2}$, were recorded.

Times with $\mathrm{SpO}_{2}$ above, within, and below the target range [ $92 \%$ to $96 \%$ ] were reported as percentage of the recorded time. These latter defined, respectively, hyperoxemia $\left(\mathrm{SpO}_{2} \geq 97 \%\right)$, normoxemia $\left(\mathrm{SpO}_{2} \geq 92 \%\right.$ and $\left.\mathrm{SpO}_{2} \leq 96 \%\right)$, and hypoxemia $\left(\mathrm{SpO}_{2} \leq 91 \%\right)$. These percentages of time were used to compare the two profiles in the first part of the study and to compare the $\mathrm{FiO}_{2}$ controller and the control groups in the second part. The differences between the two slopes studied in the first part of the study were considered small enough to justify grouping together all data obtained with the $\mathrm{FiO}_{2}$ controller. The percentage of time spent within the target range was the primary outcome variable of efficacy, and the percentage of time spent outside the target was the outcome variable of safety.

\section{Statistical analysis}

Statistical analysis was performed by using SPSS (SPSS 16.0; SPSS Inc, Chicago, IL, USA). Descriptive statistics (median and 25th and 75th percentiles) were used to summarize demographic characteristics and ventilation and blood gases baseline values. $\mathrm{SpO}_{2}$ percentages were presented as means with standard deviations. In the first part of the study, a Mann-Whitney $U$ test was used to determine whether baseline characteristics (ventilation, blood gases, scores) were significantly different between the two groups of 10 patients separated on the median value of the $\mathrm{PaO}_{2} / \mathrm{FiO}_{2}$ ratio. We performed pairwise comparisons by using the Wilcoxon test to compare the two profiles in each group. In the second part, a $t$ test was used to determine the significance of the difference between the study group and the historical group.

\section{Results}

\section{First part}

Patients

Twenty-two patients were enrolled in the study (sixteen men and six women), and two patients could not complete the study (the first one experienced selfextubation after 2 hours of recordings, and the second one's condition was severely worsened before starting the trial). All 20 patients tolerated the adjustments and completed both tests. We classified the 20 included patients into two categories of hypoxemia, according to their median $\mathrm{PaO}_{2} / \mathrm{FiO}_{2}$ ratio. Table 1 describes the characteristics of the two groups. They were comparable except for an older age in the moderately hypoxemic patients. Table 2 shows ventilation parameters and arterial blood gases. Tidal volume was higher and $\mathrm{FiO}_{2}$ lower in the moderately hypoxemic patients. For arterial blood gases, only oxygenation was significantly different between the two groups $(P<0.001)$.

\section{Hypoxemia, normoxemia, and hyperoxemia}

Figure 1 shows an example of a patient's recording: normoxemia was maintained by the $\mathrm{FiO}_{2}$ controller during 98.0\% of the recording time; hyperoxemia represented $2.0 \%$, and hypoxemia, $0.1 \%$. $\mathrm{FiO}_{2}$ set by the research nurse and suggested by the $\mathrm{FiO}_{2}$ controller were continuously recorded. More than $98 \%$ of the time, the research nurse followed the $\mathrm{FiO}_{2}$-controller suggestions.

Table 3 compares the amount of time that patients spent within and outside the target $\mathrm{SpO}_{2}$. Periods corresponding to an absence of signal and when it was not valid were also recorded. According to these criteria, we compared the two profiles (slopes of response designed for severely hypoxemic and moderately hypoxemic patients) in each group.

The percentage of time spent in the target range was higher than $95 \%$ in all cases. The severely hypoxemic profile was slightly better $(P<0.05)$ for the morehypoxemic patients $\left(\mathrm{PaO}_{2} / \mathrm{FiO}_{2}<188\right)$ to keep them in normoxemia. The number of suctioning episodes were calculated in each group and reported in Additional file 1: Table S1. For these maneuvers, no specific protocol was defined.

\section{Second part \\ Patients}

Thirty patients were included in the analysis for the control group. All patients were mechanically ventilated within the first 24 hours after ICU admission. Data about severity of illness, respiratory diagnosis, and demographic characteristics are given in Additional file 2: Table S2. A subgroup of 17 patients had a prescribed lower $\mathrm{SpO}_{2}$ threshold of $92 \%$ (that is, identical lower $\mathrm{SpO}_{2}$ threshold than with the $\mathrm{FiO}_{2}$ controller), and was also analyzed 
Table 1 Baseline characteristics of the patients

\begin{tabular}{|c|c|c|c|}
\hline Variable & $\begin{array}{l}\text { Severe hypoxemia } \\
\qquad(n=10)\end{array}$ & $\begin{array}{l}\text { Moderate hypoxemia } \\
\qquad(n=10)\end{array}$ & $P$ value \\
\hline Age, years & $65(49-69)$ & $76(72-83)$ & 0.029 \\
\hline Sex, male/female & $7 / 3$ & $7 / 3$ & \\
\hline Height, cm & $175(171-183)$ & $170(161-177)$ & 0.190 \\
\hline Weight, kg & $71(66-77)$ & $66(58-75)$ & 0.315 \\
\hline Heart rate, beats per minute & $88(74-105)$ & $84(75-96)$ & 0.393 \\
\hline APACHE II, at ICU admission & $27(24-30)$ & $31(26-33)$ & 0.165 \\
\hline SAPS II, at ICU admission & $53(51-58)$ & $56(43-66)$ & 0.684 \\
\hline SOFA, at day of recording & $7(7-9)$ & $11(9-13)$ & 0.052 \\
\hline RASS, at day of recording & $-4(-4$ to -1$)$ & $-1(-3$ to -1$)$ & 0.631 \\
\hline Mechanical ventilation, days & $4(2-7)$ & $3(1-5)$ & 0.393 \\
\hline ICU stay, days & $4(2-7)$ & $4(1-8)$ & 0.579 \\
\hline \multicolumn{4}{|l|}{ Respiratory diagnosis, $n$ (\%) } \\
\hline Pneumonia & $3(23)$ & $1(10)$ & \\
\hline Acute pulmonary edema & $1(8)$ & $0(0)$ & \\
\hline COPD & $4(31)$ & $2(20)$ & \\
\hline ARDS & $3(23)$ & $0(0)$ & \\
\hline Other & $2(15)$ & $7(70)$ & \\
\hline \multicolumn{4}{|l|}{ Equipment, $n$} \\
\hline Endotracheal tube/tracheostomy & $9 / 1$ & $9 / 1$ & \\
\hline Diameter of the tube, $\mathrm{mm}$ & $8.0(7.5-8.0)$ & $7.5(7.5-8.0)$ & 0.165 \\
\hline
\end{tabular}

APACHE, Acute Physiology and Chronic Health Evaluation; ICU, intensive care unit; SAPS, Simplified Acute Physiology Score; RASS, Richmond Agitation Sedation Scale. ARDS, acute respiratory distress syndrome; COPD, chronic obstructive pulmonary disease. "Other" patients had cardiogenic shock (three), cardiac surgery, spine surgery, cardiorespiratory arrest, or liver failure. One patient could be considered to have a normal lung.

Table 2 Ventilation and arterial blood gases of the patients

\begin{tabular}{|c|c|c|c|}
\hline Variable & $\begin{array}{l}\text { Severe hypoxemia } \\
(n=10)\end{array}$ & $\begin{array}{l}\text { Moderate hypoxemia } \\
\qquad(n=10)\end{array}$ & $\begin{array}{c}P \\
\text { value }\end{array}$ \\
\hline \multicolumn{4}{|l|}{ Ventilator mode at study inclusion, $n(\%)$} \\
\hline Pressure support ventilation & $14(70)$ & $14(70)$ & \\
\hline Pressure control ventilation & $3(15)$ & $5(25)$ & \\
\hline Volume assist control ventilation & $2(10)$ & $1(5)$ & \\
\hline Synchronized Intermittent Mandatory Ventilation & $1(5)$ & $0(0)$ & \\
\hline \multicolumn{4}{|l|}{ Ventilator settings (in the morning) } \\
\hline$M V$ exp,VL & $10(10-12)$ & $8(7-10)$ & 0.123 \\
\hline Tidal volume, $\mathrm{ml} / \mathrm{kg}$ predicted body weight & $7(6-8)$ & $9(7-10)$ & 0.011 \\
\hline Positive end-expiratory pressure, $\mathrm{cm} \mathrm{H}_{2} \mathrm{O}$ & $5(5-7)$ & $7(5-8)$ & 0.393 \\
\hline Peak inspiratory pressure, $\mathrm{cm} \mathrm{H}_{2} \mathrm{O}$ & $20(17-25)$ & $22(18-25)$ & 0.853 \\
\hline Inspired fraction of oxygen, \% & $40(40-45)$ & $30(25-35)$ & 0.001 \\
\hline \multicolumn{4}{|l|}{ Arterial blood gases (in the morning) } \\
\hline $\mathrm{pH}$ & $7.45(7.39-7.48)$ & $7.40(7.38-7.44)$ & 0.247 \\
\hline $\mathrm{PaO}_{2}, \mathrm{~mm} \mathrm{Hg}$ & $69(63-71)$ & $76(72-79)$ & 0.005 \\
\hline $\mathrm{PaCO}_{2}, \mathrm{~mm} \mathrm{Hg}$ & $38(35-54)$ & $39(35-42)$ & 0.796 \\
\hline $\mathrm{SaO}_{2}, \%$ & 94 (93-95) & $97(96-97)$ & 0.001 \\
\hline $\mathrm{PaO}_{2} / \mathrm{FiO}_{2}, \mathrm{~mm} \mathrm{Hg}$ & 160 (133-176) & $239(201-285)$ & $<0.001$ \\
\hline
\end{tabular}




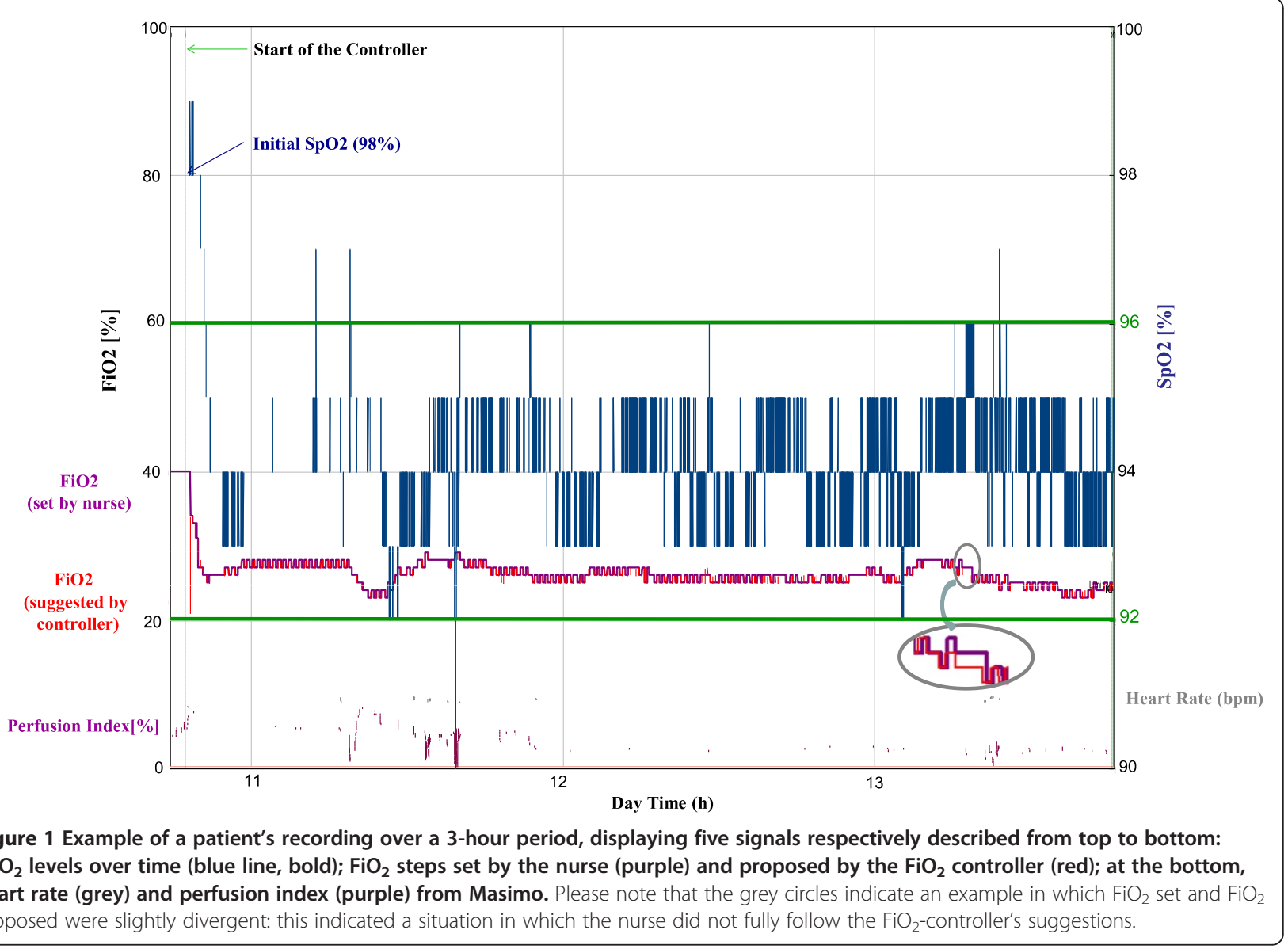

separately from the historical group. Additional file 3: Table S3 presents ventilation and blood gases for both groups.

\section{Group comparison}

We compared the study group with the historical groups to assess the efficiency of the $\mathrm{FiO}_{2}$ controller in maintaining the $\mathrm{SpO}_{2}$ within the target range and reducing time in hyperoxemia and hypoxemia. For both historical groups, we selected three periods of 6 hours: after admission in the ICU, after 24 hours, and after 7 days $(n=25)$, and the results are presented in Figures 2 and 3, which illustrate the distribution of the time spent in the different $\mathrm{SpO}_{2}$ ranges in the $\mathrm{FiO}_{2}$ controller group and in the control groups. All comparisons between the study group and both historical groups were significant, showing a shorter time spent both in hyperoxemia and in hypoxemia with the automatic $\mathrm{FiO}_{2}$ controller (see Additional file 4: Table S4). In the historical group, a slight decrease in hypoxemia $\left(\mathrm{SpO}_{2} \leq 91 \%\right)$ and hyperoxemia $\left(\mathrm{SpO}_{2} \geq 97 \%\right)$ periods was found after 7 days after admission compared with the other two periods.

Table 3 Percentage of time spent in different $\mathrm{SpO}_{2}$ ranges in each group according to the two controller profiles

\begin{tabular}{|c|c|c|c|c|c|c|}
\hline \multirow[t]{2}{*}{ Group } & \multicolumn{3}{|c|}{$\begin{array}{l}\text { Severe hypoxemia group } \\
\qquad(n=10)\end{array}$} & \multicolumn{3}{|c|}{$\begin{array}{l}\text { Moderate hypoxemia group } \\
\qquad(n=10)\end{array}$} \\
\hline & SH-profile & MH-profile & $P$ value & SH-profile & MH-profile & $P$ value \\
\hline Time with no signal (\%) & $0.1 \pm 0.2$ & $0.1 \pm 0.2$ & 0.686 & $0.4 \pm 0.5$ & $0.1 \pm 0.1$ & 0.050 \\
\hline Time with SIQ $\leq 0.3(\%)$ & $0.1 \pm 0.2$ & $0.1 \pm 0.2$ & 1.000 & $0.3 \pm 0.6$ & $0.0 \pm 0.0$ & 0.072 \\
\hline Time with hypoxemia $\left(\mathrm{SpO}_{2} \leq 91 \%\right)(\%)$ & $1.7 \pm 2.2$ & $1.9 \pm 1.9$ & 0.859 & $1.2 \pm 1.0$ & $1.0 \pm 1.0$ & 0.721 \\
\hline Time with normoxemia $\left(\mathrm{SpO}_{2}(92 \%\right.$ to $\left.96 \%)\right)(\%)$ & $96.7 \pm 4.2$ & $95.2 \pm 4.8$ & 0.047 & $95.1 \pm 4.2$ & $97.3 \pm 2.8$ & 0.074 \\
\hline Time with hyperoxemia $\left(\mathrm{SpO}_{2} \geq 97 \%\right)(\%)$ & $1.4 \pm 2.1$ & $2.8 \pm 3.0$ & 0.059 & $3.0 \pm 3.0$ & $1.6 \pm 2.1$ & 0.074 \\
\hline
\end{tabular}

$\mathrm{SIQ}$, Signal Index Quality; SH, severely hypoxemic; $\mathrm{MH}$, moderately hypoxemic. 


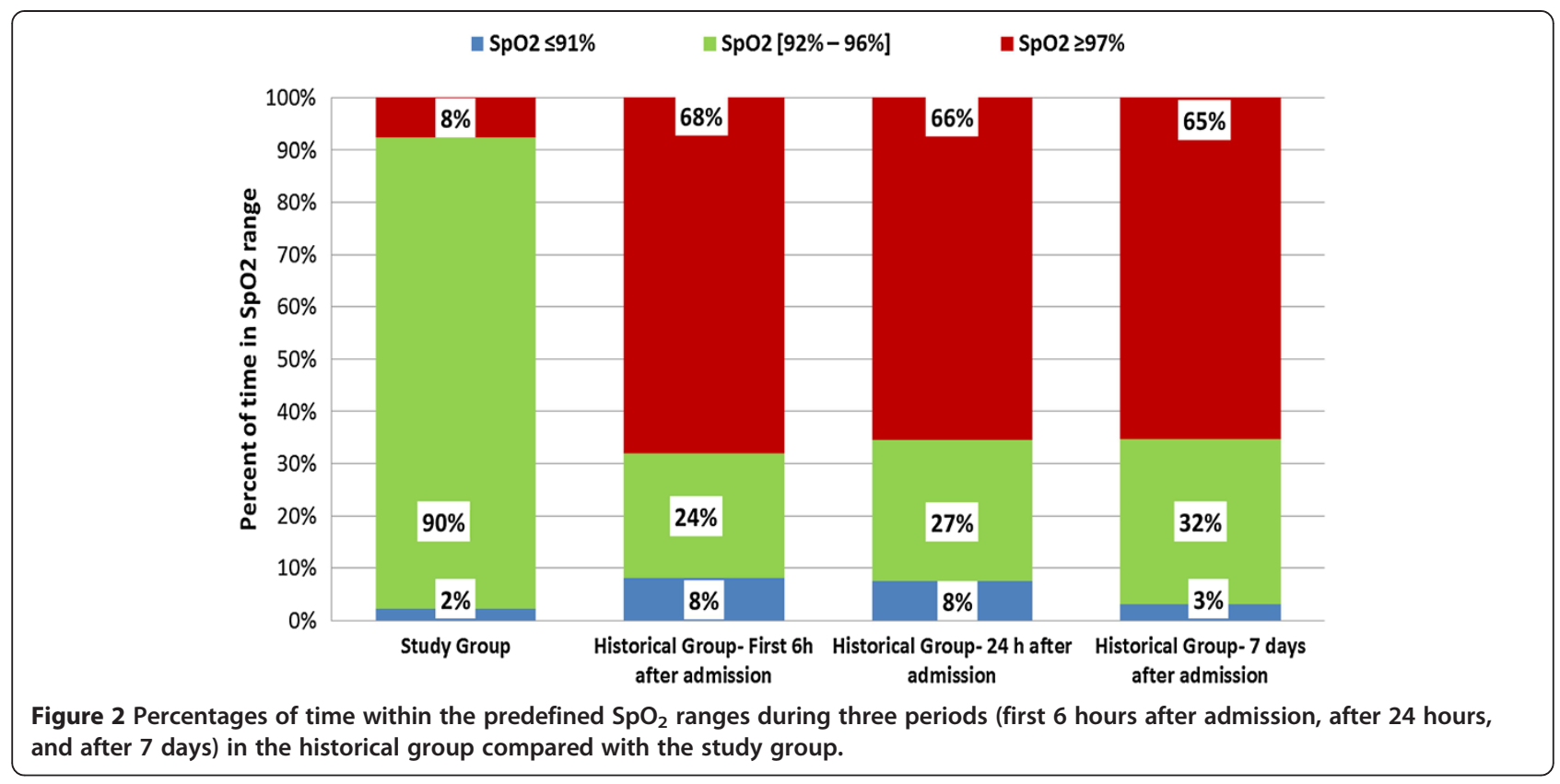

\section{Discussion}

The study showed that a specific open-loop $\mathrm{FiO}_{2}$ controller is able to maintain $\mathrm{SpO}_{2}$ reliably within a predefined target range. The time spent in the defined range is much higher than in clinical practice, because of reduced time both in hyperoxemia and in hypoxemia. Although differences between the two $\mathrm{FiO}_{2}-\mathrm{SpO}_{2}$ slopes of responses are relatively small, each profile was well adapted to each category of patients.

The historical group in our study, in accordance with the literature, suggests that the situation of oxygenation control can be improved. In ICUs, considerable variations exist in the attitude toward oxygen management. A survey among New Zealand and Australian intensivists showed a large variation in practices [21]: for instance, for a ventilated acute respiratory distress syndrome patient, $37 \%$ of respondents would not allow $\mathrm{SaO}_{2}$ of $<85 \%$ for $\leq 15$ minutes, and $28 \%$ would not allow $\mathrm{SaO}_{2}<90 \%$ for $>24$ hours. Hypoxemia is a major concern to clinicians, whereas hyperoxemia is often left out of consideration. A Canadian questionnaire study showed that most respondents prevent much more hypoxemia than hyperoxemia

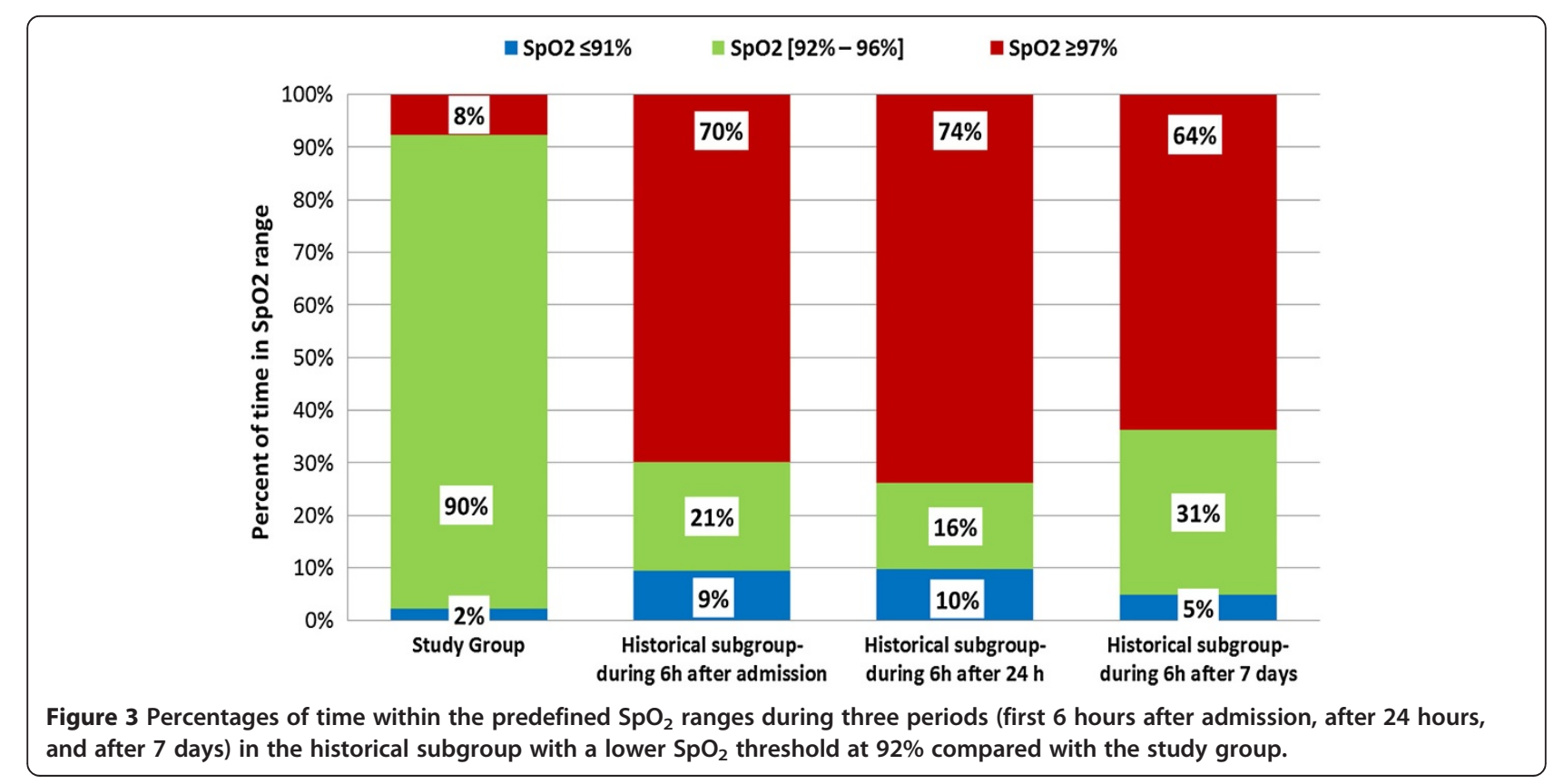


[8]. A recent Dutch study [22] showed that, in terms of minimizing hyperoxemia, intensivists are simply guided by reducing $\mathrm{FiO}_{2}$ to levels presumed to be nontoxic, with little concern for $\mathrm{PaO}_{2}$ level.

Several recent clinical observations have, however, suggested that liberal administration of oxygen can be toxic. In an observational multicenter study concerning patients admitted after resuscitation from cardiac arrest, those exposed to hyperoxemia $\left(\mathrm{PaO}_{2} \geq 300 \mathrm{~mm} \mathrm{Hg}\right)$ experienced increased mortality compared with both normoxemic and hypoxemic groups $\left(\mathrm{PaO}_{2}<60 \mathrm{~mm} \mathrm{Hg}\right)$ [2]. Administering supplemental oxygen to coronary heart disease (CHD) patients with the goal of maintaining 100\% saturation might result in vasoconstriction in the coronary circulation and hemodynamic instability [3]. In a general ICU population, both low $\mathrm{PaO}_{2}$ and high $\mathrm{PaO}_{2}$ during the first 24 hours after ICU admission were associated with hospital mortality, forming a U-shaped curve [1].

Another study found only an association between hypoxemia and increased in-hospital mortality [23]. Recently, Rachmale et al. [24] evaluated prospectively the electronic medical record screening of 289 ICU patients with acute lung injury to assess excessive oxygen exposure and its effect on pulmonary outcomes. Excessive $\mathrm{FiO}_{2}$ was defined as $\mathrm{FiO}_{2}>0.5$, despite $\mathrm{SpO}_{2}>92 \%$, and results showed that $74 \%$ of the included patients were exposed to it. The authors demonstrated a correlation between prolonged $\mathrm{FiO}_{2}$ exposure and worsening of oxygenation index at 48 hours and an association with longer duration of mechanical ventilation and ICU stay.

In our study, the potential of the automatic controller is best shown with the comparison of the time spent in hypoxemia with the historical subgroup. This subgroup had a prescribed lower $\mathrm{SpO}_{2}$ threshold of $92 \%$, but no upper limitation. The $\mathrm{FiO}_{2}$ controller showed better results in preventing hypoxemia, at the same time, keeping the time with hyperoxemia to a minimum and thus maximizing time in normoxemia.

In accordance with current ICU practice, the monitoring of oxygenation was based on pulse oximetry that continuously and noninvasively measures $\mathrm{SpO}_{2}$. Pulse oximetry has been shown to be a reliable technique for measuring the oxygen level and reduces the frequency of blood gas analysis [25-28]. Pulse oximetry has limitations, as, for example, artifacts due to patient motion, and low perfusion [29,30]. Among pulse-oximetry technologies, Signal Extraction Technology, as used by Masimo, seems to have superior performance compared with other pulseoximetry technologies in terms of motion and artifact, false alarms, and data dropout [31-34]. In neonatology, such technology has been shown helpful in reducing severe retinopathy of prematurity in preterm infants treated with supplemental oxygen [35].
With the use of pulse oximetry and computer technology, several attempts have been made to automatize the adjustment of $\mathrm{FiO}_{2}$, especially in neonatology because of the frequent and unpredictable change of oxygenation and risks of hyperoxemia in premature babies [9-12,19,36]. This automation has rarely been proposed to adults to guide the clinician to the most appropriate $\mathrm{FiO}_{2}$, apart from research. A closed-loop control of oxygenation used in military trauma patients demonstrated its efficiency at reducing oxygen needs and showed that even severely injured trauma patients can be managed with $\mathrm{FiO}_{2}<0.30$ [37]. Rees et al. [38] created a decision support system that provides advice about $\mathrm{FiO}_{2}$ setting, tidal volume, and frequency rate based on physiological models. The system has been tested retrospectively and prospectively in a few patients to evaluate its ability to provide appropriate $\mathrm{FiO}_{2}$ suggestions and has shown better $\mathrm{FiO}_{2}$ selection in comparison with attending clinicians in intensive care patients $[39,40]$. A system that automatically controls oxygen administration during nasal oxygen therapy has been proposed, based on $\mathrm{SpO}_{2}$ measurements [16]. A fully controlled ventilation system was also compared with usual care in a randomized controlled trial of postoperative patients after cardiac surgery [18]. Both ventilation and $\mathrm{FiO}_{2}$ were automatically controlled with a target for $\mathrm{SpO}_{2}$ of $94 \%$ to $98 \%$. The patients in the automated ventilation arm spent less time in nonacceptable ventilation zones, but very few details were specifically given concerning oxygenation.

We adapted an open-loop inspired oxygen control system for use in adults that has been recently tested successfully on intensive care neonates used in a closed-loop manner [41]. We designed two profiles, with the hypothesis that the more-hypoxemic patients, as defined by the lowest $\mathrm{PaO}_{2} /$ $\mathrm{FiO}_{2}$ ratio, would be less sensitive to $\mathrm{FiO}_{2}$ changes because of intrapulmonary shunt. This was confirmed in the clinical study, although the differences between the two slopes were modest. A clinician could use the classic threshold of $200 \mathrm{~mm} \mathrm{Hg}$ of $\mathrm{PaO}_{2} / \mathrm{FiO}_{2}$ ratio to select the best slope, but if the other slope were to be selected, the results would remain safe.

\section{Limits of the study}

First, the automated $\mathrm{FiO}_{2}$-controller prototype tested in the present study presents some technologic limits because it depends on the reliability and the accuracy of $\mathrm{SpO}_{2}$ and adjusts only the $\mathrm{FiO}_{2}$. It does not adjust the PEEP level, for instance. Such a system must also contain alarms alerting the clinician when consistent and substantial changes in $\mathrm{FiO}_{2}$ are observed; otherwise, a risk would be to reduce the attentiveness of the caregiver and delay recognition of changes in respiratory function. These alarms were not specifically tested with the open loop. We excluded patients with hemodynamic instability 
to limit the risk of deterioration of the patient and did not face any problem because of low signal-quality measurement. The controller algorithm is also able to validate the $\mathrm{SpO}_{2}$ signal quality and enters into a fall-back state, keeping $\mathrm{FiO}_{2}$ constant. This condition must be investigated to test the reliability of the system in extreme conditions. Last, the experimental design gave us the unique opportunity to compare the system with usual care but could not permit us to assess the workload reduction expected with the automatic system. The 6-hour period tested in the present study is relatively short. When we investigated different time windows in the control group, however, they all looked very similar, suggesting that these 6hour periods are meaningful and representative.

\section{Conclusion}

The tested open-loop system allowed maintaining $\mathrm{SpO}_{2}$ within a target range and decreased hyperoxemia and hypoxemia periods in comparison with usual care. It could provide physiological and clinical benefits to patients. As with every automated system, it requires an understanding of its operation and vigilance. This study opens the perspective for a test in a closed loop in comparison with usual care.

\section{Key messages}

- An automated $\mathrm{FiO}_{2}$ controller based on oxygen-saturation measurement is able to maintain $\mathrm{SpO}_{2}$ reliably in a safety-predefined range during mechanical ventilation of adult critically ill patients.

- The Automatic $\mathrm{FiO}_{2}$ controller exhibits excellent performance in adjusting $\mathrm{FiO}_{2}$ at different levels of baseline $\mathrm{PaO}_{2} / \mathrm{FiO}_{2}$ ratio.

- Automatic adjustment of $\mathrm{FiO}_{2}$ was able to maintain $\mathrm{SpO}_{2}$ in a predefined target range much better compared with a historical group of mechanically ventilated patients.

\section{Additional files}

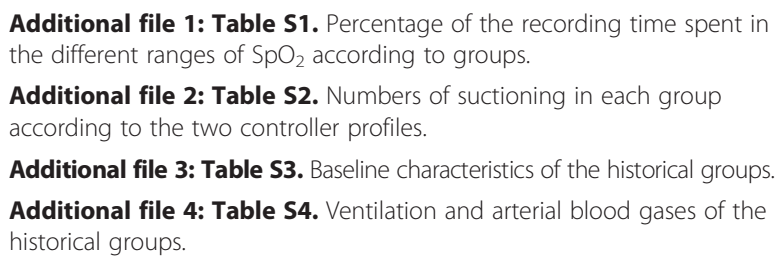

Additional file 2: Table S2. Numbers of suctioning in each group according to the two controller profiles.

Additional file 3: Table S3. Baseline characteristics of the historical groups. Additional file 4: Table S4. Ventilation and arterial blood gases of the historical groups.

\section{Abbreviations}

APACHE II: Acute Physiology and Chronic Health Evaluation II; ARDS: acute respiratory distress syndrome; COPD: chronic obstructive pulmonary disease; $\mathrm{FiO}_{2}$ : fraction of inspired oxygen; ICU: intensive care unit; $\mathrm{MH}$ : moderately hypoxemic; $\mathrm{PaCO}_{2}$ : carbon dioxide partial pressure; $\mathrm{PaO}_{2}$ : arterial oxygen partial pressure; $\mathrm{PaO}_{2} / \mathrm{FiO}_{2}$ ratio: ratio of arterial oxygen partial pressure to fraction of inspired oxygen; PEEP: positive end-expiratory pressure;
RASS: Richmond Agitation Sedation Scale; $\mathrm{SaO}_{2}$ : arterial oxygen saturation; SAPS II: Simplified Acute Physiology Score II; SH: severely hypoxemic; Signal IQ: Signal Index Quality; $\mathrm{SpO}_{2}$ : arterial oxygen saturation by pulse oximetry.

\section{Competing interests}

Kaouther Saihi was recipient of a grant co-funded by the Ministry of Industry (France) and Dräger Company (grant CIFRE 1323/2010).

Laurent Brochard, Michel Dojat, and the research laboratory in Geneva received funding as consultants for the project.

Xavier Gonin was hired as a research nurse by a grant from Dräger.

Thomas Krüger is an employee of Dräger Medical, Lübeck, Germany.

\section{Authors' contributions}

KS contributed to design the study protocol, to the measurements, to historical data collection, performed the statistical analysis, prepared the figures, and drafted the manuscript. J-C M R participated in the study design, to interpret the results, and helped in editing the manuscript. XG actively participated in all patients' recordings and helped with historical data analysis. TK and MD actively contributed to design the study, to interpret the data, and helped in editing the final version of the manuscript. TK was involved in the design and development of the automated $\mathrm{FiO}_{2}$ controller. $\mathrm{LB}$ coordinated and participated in all steps of the study from protocol design to the writing and editing process of the manuscript. All authors read and approved the final version of the manuscript.

\section{Acknowledgements}

We are indebted to Aissam Lyazidi, biomedical engineer, for valuable contribution in editing the reference list. Particular acknowledgements go to Mrs. Delieuvin Schmitt Nathalie, specialized nurse, for her help in data collection.

\section{Author details}

${ }^{1}$ Intensive Care Unit, Department of Anesthesiology, Pharmacology and Intensive Care, Geneva University Hospital, Geneva, Switzerland. 'Dräger Medical GmbH, Lübeck, Germany. ${ }^{3}$ Grenoble Institut of Neurosciences (GIN)—INSERM U836 \& Joseph Fourier University, Grenoble, France. ${ }^{4}$ Critical Care Department, St Michael's Hospital, Toronto; InterDepartmental Division of Critical care Medicine University of Toronto, Toronto, Canada.

Received: 26 August 2013 Accepted: 24 January 2014

Published: 19 February 2014

\section{References}

1. de Jonge E, Peelen L, Keijzers PJ, Joore H, de Lange D, van der Voort PH, Bosman RJ, de Waal RA, Wesselink R, de Keizer NF: Association between administered oxygen, arterial partial oxygen pressure and mortality in mechanically ventilated intensive care unit patients. Crit Care 2008, 12:R156.

2. Kilgannon JH, Jones AE, Shapiro NI, Angelos MG, Milcarek B, Hunter K, Parrillo JE, Trzeciak S: Association between arterial hyperoxia following resuscitation from cardiac arrest and in-hospital mortality. JAMA 2010, 303:2165-2171.

3. McNulty PH, King N, Scott S, Hartman G, McCann J, Kozak M, Chambers CE, Demers LM, Sinoway LI: Effects of supplemental oxygen administration on coronary blood flow in patients undergoing cardiac catheterization. Am J Physiol Heart Circ Physiol 2005, 288:H1057-H1062.

4. Altemeier WA, Sinclair SE: Hyperoxia in the intensive care unit: why more is not always better. Curr Opin Crit Care 2007, 13:73-78.

5. Aboab J, Jonson B, Kouatchet A, Taille S, Niklason L, Brochard L: Effect of inspired oxygen fraction on alveolar derecruitment in acute respiratory distress syndrome. Intensive Care Med 2006, 32:1979-1986.

6. Croxton TL, Bailey WC: Long-term oxygen treatment in chronic obstructive pulmonary disease: recommendations for future research: an NHLBI workshop report. Am J Respir Crit Care Med 2006, 174:373-378.

7. Davis DP, Meade W, Sise MJ, Kennedy F, Simon F, Tominaga G, Steele J, Coimbra R: Both hypoxemia and extreme hyperoxemia may be detrimental in patients with severe traumatic brain injury. J Neurotrauma 2009, 26:2217-2223.

8. Mao C, Wong DT, Slutsky AS, Kavanagh BP: A quantitative assessment of how Canadian intensivists believe they utilize oxygen in the intensive care unit. Crit Care Med 1999, 27:2806-2811. 
9. Claure N, D'Ugard C, Bancalari E: Automated adjustment of inspired oxygen in preterm infants with frequent fluctuations in oxygenation: a pilot clinical trial. J Pediatr 2009, 155:640-645. e1-2.

10. Claure N, Gerhardt T, Everett R, Musante G, Herrera C, Bancalari E: Closed-loop controlled inspired oxygen concentration for mechanically ventilated very low birth weight infants with frequent episodes of hypoxemia. Pediatrics 2001, 107:1120-1124.

11. Tehrani FT, Abbasi S: Evaluation of a computerized system for mechanical ventilation of infants. J Clin Monit Comput 2009, 23:93-104.

12. Urschitz MS, Horn W, Seyfang A, Hallenberger A, Herberts T, Miksch S, Popow C, Muller-Hansen I, Poets CF: Automatic control of the inspired oxygen fraction in preterm infants: a randomized crossover trial. Am J Respir Crit Care Med 2004, 170:1095-1100.

13. Cirio S, Nava S: Pilot study of a new device to titrate oxygen flow in hypoxic patients on long-term oxygen therapy. Respir Care 2011, 56:429-434.

14. Johannigman JA, Branson R, Lecroy D, Beck G: Autonomous control of inspired oxygen concentration during mechanical ventilation of the critically injured trauma patient. J Trauma 2009, 66:386-392.

15. Rice KL, Schmidt MF, Buan JS, Lebahn F, Schwarzock TK: AccuO2 oximetry-driven oxygen-conserving device versus fixed-dose oxygen devices in stable COPD patients. Respir Care 2011, 56:1901-1905.

16. Lellouche F, L'Her E: Automated oxygen flow titration to maintain constant oxygenation. Respir Care 2012, 57:1254-1262.

17. Arnal JM, Wysocki M, Novotni D, Demory D, Lopez R, Donati S, Granier I, Corno G, Durand-Gasselin J: Safety and efficacy of a fully closed-loop control ventilation (IntelliVent-ASV(R)) in sedated ICU patients with acute respiratory failure: a prospective randomized crossover study. Intensive Care Med 2012, 38:781-787.

18. Lellouche F, Bouchard PA, Simard S, L'Her E, Wysocki M: Evaluation of fully automated ventilation: a randomized controlled study in post-cardiac surgery patients. Intensive Care Med 2013, 39:463-471.

19. Urschitz MS, Von EV, Seyfang A, Poets CF: Use of pulse oximetry in automated oxygen delivery to ventilated infants. Anesth Analg 2002, 94:S37-S40.

20. Claure N, Bancalari E: Automated closed loop control of inspired oxygen concentration. Respir Care 2013, 58:151-161.

21. Eastwood GM, Reade MC, Peck L, Jones D, Bellomo R: Intensivists' opinion and self-reported practice of oxygen therapy. Anaesth Intensive Care 2011, 39:122-126.

22. de Graaff $A E$, Dongelmans DA, Binnekade JM, de Jonge E: Clinicians' response to hyperoxia in ventilated patients in a Dutch ICU depends on the level of $\mathrm{FiO}_{2}$. Intensive Care Med 2011, 37:46-51.

23. Eastwood G, Bellomo R, Bailey M, Taori G, Pilcher D, Young P, Beasley R: Arterial oxygen tension and mortality in mechanically ventilated patients. Intensive Care Med 2012, 38:91-98.

24. Rachmale S, Li G, Wilson G, Malinchoc M, Gajic O: Practice of excessive F $(\mathrm{IO}(2))$ and effect on pulmonary outcomes in mechanically ventilated patients with acute lung injury. Respir Care 2012, 57:1887-1893.

25. Inman KJ, Sibbald WJ, Rutledge FS, Speechley M, Martin CM, Clark BJ: Does implementing pulse oximetry in a critical care unit result in substantial arterial blood gas savings? Chest 1993, 104:542-546.

26. Jubran A: Pulse oximetry. Intensive Care Med 2004, 30:2017-2020.

27. Jubran A, Tobin MJ: Reliability of pulse oximetry in titrating supplemental oxygen therapy in ventilator-dependent patients. Chest 1990, 97:1420-1425.

28. Roizen MF, Schreider B, Austin W, Carter C, Polk S: Pulse oximetry, capnography, and blood gas measurements: reducing cost and improving the quality of care with technology. J Clin Monit 1993, 9:237-240.

29. Plummer $\mathrm{L}$, Zakaria $A Z$, Ilsley $A H$, Fronsko RR, Owen $\mathrm{H}$ : Evaluation of the influence of movement on saturation readings from pulse oximeters. Anaesthesia 1995, 50:423-426.

30. Wiklund L, Hok B, Stahl K, Jordeby-Jonsson A: Postanesthesia monitoring revisited: frequency of true and false alarms from different monitoring devices. J Clin Anesth 1994, 6:182-188.

31. Bohnhorst B, Peter CS, Poets CF: Detection of hyperoxaemia in neonates: data from three new pulse oximeters. Arch Dis Child Fetal Neonatal Ed 2002, 87:F217-F219.

32. Gerstmann D, Berg R, Haskell R, Brower C, Wood K, Yoder B, Greenway L, Lassen G, Ogden R, Stoddard R, Minton S: Operational evaluation of pulse oximetry in NICU patients with arterial access. J Perinato/ 2003, 23:378-383.

33. Poets CF, Urschitz MS, Bohnhorst B: Pulse oximetry in the neonatal intensive care unit (NICU): detection of hyperoxemia and false alarm rates. Anesth Analg 2002, 94:S41-S43.
34. Malviya S, Reynolds PI, Voepel-Lewis T, Siewert M, Watson D, Tait AR, Tremper K: False alarms and sensitivity of conventional pulse oximetry versus the Masimo SET technology in the pediatric postanesthesia care unit. Anesth Analg 2000, 90:1336-1340.

35. Castillo A, Deulofeut R, Critz A, Sola A: Prevention of retinopathy of prematurity in preterm infants through changes in clinical practice and SpO(2) technology. Acta Paediatr 2011, 100:188-192.

36. Raemer DB, Ji XB, Topulos GP: Flx controller: an instrument to automatically adjust inspired oxygen fraction using feedback control from a pulse oximeter. J Clin Monit 1997, 13:91-101.

37. Johannigman JA, Branson RD, Edwards MG: Closed loop control of inspired oxygen concentration in trauma patients. J Am Coll Surg 2009, 208:763-768. discussion 8-9.

38. Rees SE, Allerod C, Murley D, Zhao Y, Smith BW, Kjaergaard S, Thorgaard P, Andreassen S: Using physiological models and decision theory for selecting appropriate ventilator settings. J Clin Monit Comput 2006, 20:421-429.

39. Allerod C, Rees SE, Rasmussen BS, Karbing DS, Kjaergaard S, Thorgaard P, Andreassen S: A decision support system for suggesting ventilator settings: retrospective evaluation in cardiac surgery patients ventilated in the ICU. Comput Methods Programs Biomed 2008, 92:205-212.

40. Karbing DS, Allerod C, Thorgaard P, Carius AM, Frilev L, Andreassen S, Kjaergaard S, Rees SE: Prospective evaluation of a decision support system for setting inspired oxygen in intensive care patients. J Critical Care 2010, 25:367-374

41. Gerstmann D, Null DJ: Successful use of a four-set point neonatal multi-protocol inspired oxygen controller pediatrics [abstract]. In Proceedings of the AAP national conference and exhibition. San Francisco, CA; 2010.

doi:10.1186/cc13734

Cite this article as: Saihi et al:: Feasibility and reliability of an automated controller of inspired oxygen concentration during mechanical ventilation. Critical Care 2014 18:R35.

\section{Submit your next manuscript to BioMed Central and take full advantage of:}

- Convenient online submission

- Thorough peer review

- No space constraints or color figure charges

- Immediate publication on acceptance

- Inclusion in PubMed, CAS, Scopus and Google Scholar

- Research which is freely available for redistribution

Submit your manuscript at www.biomedcentral.com/submit
C) Biomed Central 